\title{
Educando con Visión
}

Pág. 10,13

Recibido: 20 Enero 2020

Pablo Guzmán Stein, Rector de la Universidad de Ciencias

Aceptado: 25 Enero 2020

Médicas ( UCIMED ), San José Costa Rica

$\mathrm{S}$ hay un área en la que la innovación, la tecnología, la actualización, el compromiso, la calidad y excelencia se convierten en una exigencia fundamental, es en educación y para quienes estamos en el campo de las ciencias de la salud, esta exigencia es aún más relevante.

Algunas universidades así lo han entendido y se refleja en la calidad de los profesionales que están graduando. Otras, en cambio, están enfocadas en la generación de ingresos y dejan de lado estos aspectos tan importantes, esto ha llevado a cuestionamientos públicos sobre la calidad de la educación en salud, que en muchos casos son injustificados.

Creo que, por su importancia, el tema debe ser analizado de manera objetiva y valorando todos los componentes que están en juego, pues al final esta exploración es la que permitirá tener los elementos de juicio para definir cuál universidad es de calidad y cuál no.

Lo primero es entender que cuando hablamos de la innovación en la salud y en la educación, no solo estamos hablando de equipos, laboratorios o tecnologías, sino también de métodos de enseñanza, contenidos educativos y programas de estudio, docentes y todo lo relacionado con el funcionamiento de una universidad.

También debemos entender y hacer la diferencia entre innovación e investigación, dos palabras que, aunque van de la mano, obedecen a objetivos e intereses muy diferentes y son parte del ADN de cualquier universidad de prestigio en el mundo. La innovación y la investigación son prácticas fundamentales en la rutina de cualquier centro de estudios serio y se distinguirá por la prioridad y el énfasis que le dé a cada uno de estos aspectos.

La innovación también implica una reinvención y una evaluación constante de los procesos, metodologías de estudio, capacitaciones y perfiles y, aquí es cuando sumamos la palabra compromiso, pues no se trata solo de términos publicitarios o conceptos que Ilamen la atención, se trata de la convicción y la determinación con la que asumamos la calidad de los profesionales que queremos formar.

Cuando una universidad especializada en Ciencias de Salud recibe a un nuevo estudiante debe tener claro el enorme compromiso que está asumiendo, pues en sus manos está nada más y nada menos que un futuro profesional y no basta solo con darle una buena formación académica, también debe dársele las herramientas humanísticas que le permitan ejercer luego como un profesional integral.

El compromiso también se adquiere con los padres de familia, quienes normalmente deben realizar importantes inversiones para sufragar los gastos que implica una profesión en Ciencias de la Salud, el compromiso se adquiere con las entidades estatales que autorizan su funcionamiento y con el país que confía en la calidad de los profesionales que gradúa. Pero, sobre todo, este compromiso se adquiere con los pacientes, pues para muchos estará en juego su calidad de vida o su propia vida.

Es por lo anterior que la evolución hacia la perfección es un componente clave de la educación en ciencias de la salud y debe estar 
siempre presente en la formación de médicos, nutricionistas, microbiólogos, fisioterapeutas, farmacéuticos o de cualquier otro profesional en este campo y será una herramienta fundamental para marcar una diferencia en su desempeño.

Como ejemplo de esa evolución constante, existen actualmente metodologías innovadoras que buscan potenciar las capacidades de los estudiantes, a partir de la enseñanza más práctica y menos memorística.

Con estas nuevas metodologías, los profesionales están además preparados para enfrentarse a pruebas internacionales que son un requisito, cuando se desea realizar una residencia en cualquier país del mundo.

Estos métodos, incorporan diversas herramientas para estimular el pensamiento crítico, por medio de la valoración y análisis de los casos, más allá de la simple lectura para memorizar el contenido.

Debemos entender este tipo de actualizaciones como parte del compromiso con la educación de calidad, para que los futuros profesionales tengan muchas más capacidades para ejercer de forma integral, tanto en Costa Rica como fuera de sus fronteras.

Estos métodos nuevos de enseñanza incorporan el uso de plataformas académicas, que sacan provecho de la tecnología, los videos y la valoración analítica. Aquí el raciocinio es fundamental, pues se va más allá de la forma de enseñanza tradicional de la medicina u otras profesiones.

Es claro que una buena educación estará ligada con la necesidad de realizar, de forma casi permanente, importantes inversiones financieras, estas se verán reflejadas en la calidad de los profesionales, pues representan una importante oportunidad de estimular y potenciar sus capacidades, para que salgan al mundo con la preparación que tanto exigen los estándares internacionales.

¿Pero cómo tenemos plena garantía de que las universidades realmente cumplen con su compromiso de excelencia?... para ello existe también una herramienta que es la acreditación. Contamos con organismos nacionales e internacionales que pasan por la lupa a las universidades y las someten a rígidos parámetros de análisis y de evaluación para determinar que efectivamente cumplen con los requerimientos de calidad impuestos.

$Y$ aunque algunas veces estas acreditaciones son vistas como una amenaza, en realidad, son grandes aliadas para la educación de calidad y el instrumento por el cual los estudiantes y sus padres pueden tener la confianza y el conocimiento certero sobre lo que verdaderamente ofrece una determinada universidad.

Así como la globalización se generaliza cada vez más, también las universidades lo hacen y, por la enorme responsabilidad que tienen, en materia de acreditación se debe ver más allá y aspirar a estándares también globalizados. Si bien es cierto, en el país existen entidades de gran prestigio en este campo, las exigencias internacionales y esa constante búsqueda hacia la excelencia, obliga a ir más allá y buscar una acreditación internacional.

Es claro que para llegar a ese nivel de acreditación se requiere haber pasado por un sólido proceso de crecimiento que, sin lugar a duda, permitirá elevar el potencial intelectual de cada uno de los estudiantes y que será un elemento clave que les abrirá puertas en el mercado laboral en todo el mundo.

Siempreen línea con laglobalización, la innovación, la excelencia y el compromiso, hay otro elemento que nos debe preocupar y ocupar a quienes forman profesionales en el campo de la salud y me refiero a la búsqueda constante de acuerdos o convenios con las mejores universidades en el mundo y en especial con las de mayor prestigio. Estas experiencias son importantes, porque además de permitirles conocer, experimentar y mejorar sus conocimientos, también y sin lugar a duda, les abrirá sus mentes y les dará más opciones laborales. 
En algunos párrafos atrás me referí brevemente a la importancia de una formación humanística y este es un aspecto que merece ser profundizado, pues no es posible pensar en un médico, una enfermera, un fisioterapeuta o cualquier profesional en este campo, sin una sólida formación y convicción del valor de esa fuerza trasformadora que es la humanidad.

La reflexión y el pensamiento claro, sobre el valor de las personas no se agotan ni en las aulas ni en las investigaciones, sino que se alimenta de la relación cotidiana con sus pacientes y lleva a la toma de decisiones, acciones enfocadas en un trato más humanizado y comprometido y será también un factor diferenciador para reconocer a las universidades de calidad.

Atender bien a un paciente va mucho más allá de curar su enfermedad, incluye un acompañamiento asistencial e implica la interacción entre los conocimientos de la ciencia y los valores del ser humano para establecer una asistencia con calidad centrada en el individuo, a través de un vínculo. Implica acompañamiento psicológico, emocional y moral, una mirada cómplice, una sonrisa y la información necesaria sobre la enfermedad, ayudan a asimilar la dolencia que se padece y a enfrentarla con mayor efectividad.

Recordemos siempre que el enfermo en el centro de la atención es nuestra razón de ser como profesionales y tenemos la gran responsabilidad y la obligación de trasmitírselo así a nuestros estudiantes y asegurarnos que lo entiendan, lo interioricen y actúen siempre basados en estos principios.

El tema de la calidad en la educación no solo atañe a las universidades, atañe también a los jóvenes quienes deben estar conscientes que para ser buenos profesionales y tener un futuro exitoso no pueden ni deben optar por lo fácil o lo rápido. Una educación de calidad implica sacrificio, dedicación y compromiso.
Como se ha tratado de explicar en los párrafos anteriores, la educación en ciencias de la salud no puede analizarse de forma ligera o superficial y lleva implícito un enorme compromiso de sus actores.

Al final, en ciencias de la salud el buen desempeño depende de muchos factores; conocimiento, tecnología, enfoque humanístico, actualización constante. El éxito profesional solo será posible si la persona que tiene conocimiento de las ciencias básicas, biológicas, humanas, sociales, científicas, técnicas y tecnológicas las pone al servicio de cada uno de sus pacientes.

\section{(1) (9) $\Theta \Theta$}



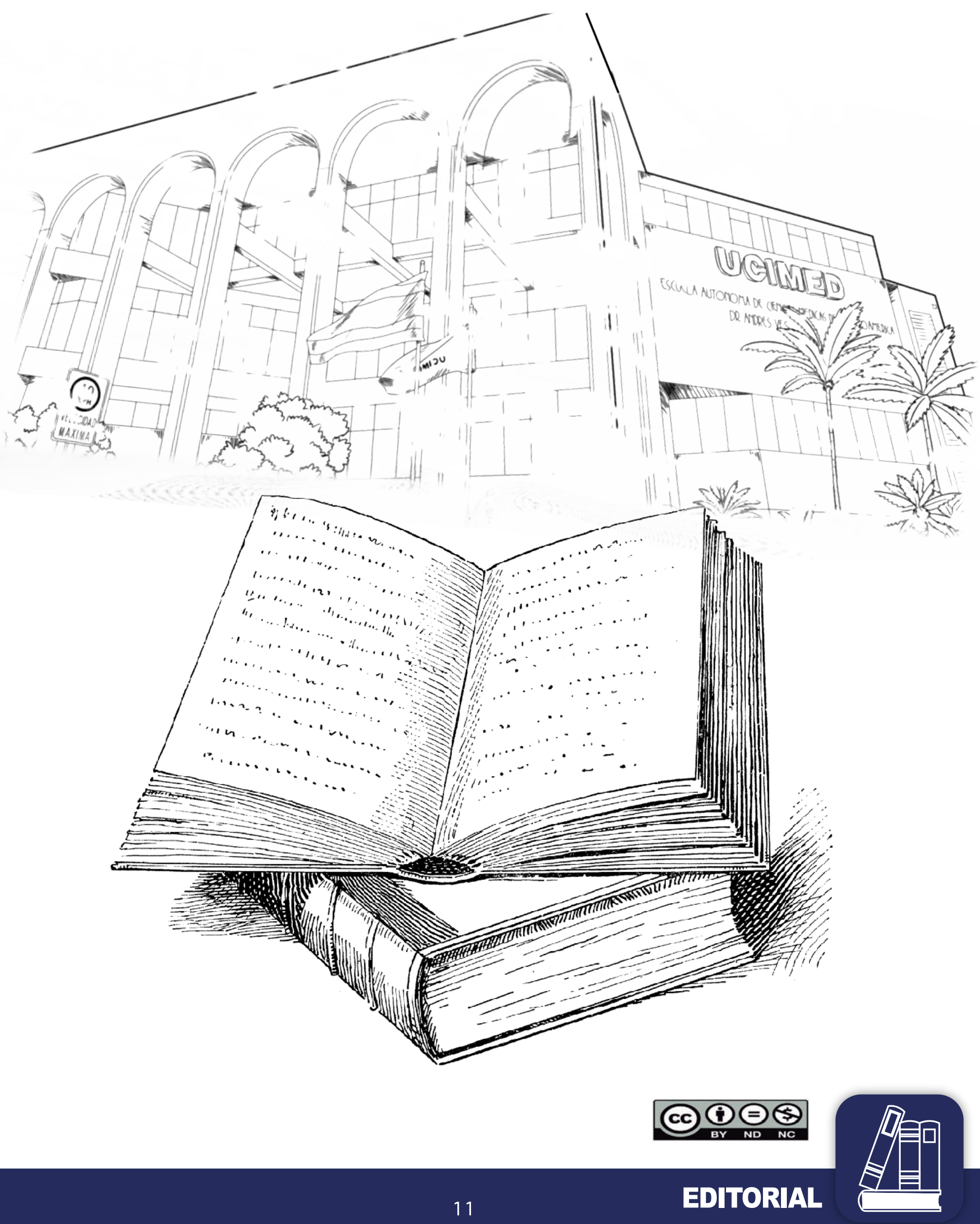